\title{
New Author Guidelines for Addressing Race and Racism in the Journal of Hospital Medicine
}

\author{
Annie Lintzenich Andrews, MD, MSCR¹, Ndidi Unaka, MD, MEd², Samir S Shah, MD, MSCE ${ }^{2 \star}$
}

${ }^{1}$ Section of Pediatric Hospital Medicine, Department of Pediatrics, Medical University of South Carolina, Charleston, South Carolina; ${ }^{2}$ Division of Hospital Medicine, Department of Pediatrics, Cincinnati Children's Hospital Medical Center and the University of Cincinnati College of Medicine, Cincinnati, Ohio.

W e are committed to using our platform at the Journal of Hospital Medicine (JHM) to address inequities in healthcare delivery, policy, and research. Race was conceived as a mechanism of social division, leading to the false belief, propagated over time, of race as a biological variable. ${ }^{1}$ As a result, racism has contributed to the medical abuse and exploitation of Black and Brown communities and inequities in health status among racialized groups. We must abandon practices that perpetuate inequities and champion practices that resolve them. Racial health equity - the absence of unjust and avoidable health disparities among racialized groups-is unattainable if we continue to simply identify inequities without naming racism as a determinant of health. As a journal, our responsibility is to disseminate evidence-based manuscripts that reflect an understanding of race, racism, and health.

We have modified our author guidelines. First, we now require authors to clearly define race and provide justification for its inclusion in clinical case descriptions and study analyses. We aim to contribute to the necessary course correction as well as promote self-reflection on study design choices that propagate false notions of race as a biological concept and conclusions that reinforce race-based rather than raceconscious practices in medicine. ${ }^{2}$ Second, we expect authors to explicitly name racism and make a concerted effort to explore its role, identify its specific forms, and examine mutually reinforcing mechanisms of inequity that potentially contributed to study findings. Finally, we instruct authors to avoid the use of phrases like "patient mistrust," which places blame for inequities on patients and their families and decouples mistrust from the fraught history of racism in medicine.

We must also acknowledge and reflect on our previous contributions to such inequity as authors, reviewers, and editors in

*Corresponding Author: Samir S Shah; Email: Samir.Shah@cchmc.org; Telephone: 513-636-6222; Twitter: @SamirShahMD.

Published online first February 1, 2021.

Received: January 11, 2021; Accepted: January 15, 2021

๑) 2021 Society of Hospital Medicine DOI 10.12788/jhm.3598 order to learn and grow. Among the more than 2,000 articles published in JHM since its inception, only four included the term "racism." Three of these articles are perspectives published in June 2020 and beyond. The only original research manuscript that directly addressed racism was a qualitative study of adults with sickle cell disease. ${ }^{3}$ The authors described study participants' perspectives: "In contrast, the hospital experience during adulthood was often punctuated by bitter relationships with staff, and distrust over possible excessive use of opioids. Moreover, participants raised the possibility of racism in their interactions with hospital staff." In this example, patients called out racism and its impact on their experience. We know JHM is not alone in falling woefully short in advancing our understanding of racism and racial health inequities. Each of us should identify missed opportunities to call out racism as a driver of racial health disparities in our own publications. We must act on these lessons regarding the ways in which racism infiltrates scientific publishing. We must use this awareness, along with our influence, voice, and collective power, to enact change for the betterment of our patients, their families, and the medical community.

We at JHM will contribute to uncovering and disseminating solutions to health inequities that result from racism. We are grateful to Boyd et al ${ }^{4}$ for their call to action and for providing a blueprint for improvement to those of us who write, review, and publish scholarly work.

Disclosure: The authors have no conflicts to disclose.

\section{References}

1. Roberts D. Fatal Invention: How Science, Politics, and Big Business Re-Create Race in the Twenty-First Century. 2nd ed. The New Press; 2012.

2. Cerdeña JP, Plaisime MV, Tsai J. From race-based to race-conscious medicine: how anti-racist uprisings call us to act. Lancet. 2020;396:1125-1128. https://doi:10.1016/S0140-6736(20)32076-6

3. Weisberg D, Balf-Soran G, Becker W, et al. "I'm talking about pain": sickle cell disease patients with extremely high hospital use. J Hosp Med. 2013;8:42-46. https://doi:10.1002/jhm.1987

4. Boyd RW, Lindo EG, Weeks LD, McLemore MR. On racism: a new standard for publishing on racial health inequities. Health Affairs Blog. July 2, 2020. Accessed January 22, 2021. https://doi:10.1377/hblog20200630.939347 https://www.healthaffairs.org/do/10.1377/hblog20200630.939347/full/ 